Article

\title{
Anti-Democratic Tenets? Behavioural-Economic Imaginaries of a Future Food System
}

\author{
Tobias Gumbert \\ Institute of Political Science, University of Münster, 48151 Münster, Germany; E-Mail: tobiasgumbert@uni-muenster.de
}

Submitted: 7 May 2019 | Accepted: 8 August 2019 | Published: 28 October 2019

\begin{abstract}
This article makes the central argument that basic democratic values such as justice, autonomy and participation run the risk of being neglected when designing 'nudges' (i.e., indirect suggestions to influence individual behaviour) for sustainable behaviour change in the context of food governance, potentially complicating a democratisation of the food system. 'Nudges' uphold freedom of choice while simultaneously advocating a non-coercive soft force of paternalism to help people realise their preferences, maximise societal well-being and meet macro-sustainability goals. While the promises of the 'nudge' approach are widely echoed, nudging is also being contested because of its possible anti-democratic effects, such as individualisation, depoliticization and the emphasis of the status of citizens as 'consumer-citizens.' From a food democracy perspective, these dangers may undermine efforts to organise collective political action and impede alternative visions of a future food system. Empirically, the article examines specifically how behavioural-economic approaches imagine transitions to a more sustainable food system. By using the "COOP Supermarket of the Future" as a case study, the following analysis will illustrate how private actors are increasingly involved in steering consumer choice towards socially desirable actions. The analysis suggests that the design of choice environments may under specific circumstances increase the susceptibility of individuals to the influence of corporate preferences and simultaneously decrease the prospects for democratic legitimation and decision-making. The article therefore critically assesses whether reforming the food system by altering consumers' choice-sets and the attribution of personal responsibility, may in fact point towards implicit antidemocratic tenets underlying the 'will to nudge' citizens.
\end{abstract}

\section{Keywords}

behaviour change; food choice; food democracy; nudging; responsibilisation; sustainable consumption

Issue

This article is part of the issue "New Perspectives on Food Democracy" edited by Basil Bornemann (University of Basel, Switzerland) and Sabine Weiland (Université Catholique de Lille, France).

(C) 2019 by the author; licensee Cogitatio (Lisbon, Portugal). This article is licensed under a Creative Commons Attribution 4.0 International License (CC BY).

\section{Introduction}

The current politics of food are subject to two simultaneous large-scale tendencies: concentration and decentralisation. On the one hand, the industrial food system is increasingly concentrated in many vital market sectors such as meat, cocoa, tea, bananas, etc. (Carolan, 2012; Clapp, 2016). The manifestation of oligopolistic structures signifies the increasing influence of a small number of transnational corporations over large systems of food production, distribution and consumption. On the other hand, non-governmental actors, grassroots initia- tives and social innovators, working towards the regionalisation and localisation of processes within the food system, are enacting alternatives that challenge the industrial food complex and its dominant rationalities regarding productivity, competition and economic growth (de Young \& Princen, 2012; Gumbert \& Fuchs, 2018; Schlosberg \& Coles, 2016). How the global food system develops and takes shape in the future, that is, if socially and ecologically sustainable practices can be upscaled to have systemic impacts, or if the corporate model of cheap labor, cheap food, and global commodity chains is solidified and expanded further, hinges on a number 
of different normative assumptions and political values that have to be scrutinized.

This study presents the concept of food democracy as instrumental to analyse these dynamics, as well as contributing towards an understanding of the barriers that are currently in place preventing food systems from moving into the direction of enhanced sustainability and justice. Pathways to a future food system are constantly envisioned and enacted by a range of different actors. Alternative lifestyles and 'food experiments' (urban gardening, food sharing networks, etc.) make sense of how we interact with food by crafting food narratives, and by establishing different material circulations of food commodities and values (Schlosberg \& Coles, 2016; Stock, Carolan, \& Rosin, 2015). These practices contain a vision of what a fair food system might look like and many actors have started to call on a wider community to recognise problems, to participate in discussions and to be hopeful that a transition is possible. And yet, contemporary policy practices in the field of food governance similarly envision necessary changes to the food system and ways to get there. They too tell stories about the most urgent problems, best practice approaches, most effective solutions and the role of politics and democracy. An increasingly important source of food system imaginaries resides in the political rationality of editing the choice sets of consumers. Behaviour change strategies, widely termed 'nudging', promise to be an effective tool for 'greening' consumption and for encouraging more sustainable lifestyles by incentivising people to behave more rationally and environmentally responsible. For these reasons, nudging has been applied to various consumption-relevant domains, such as food consumption, food purchasing and food waste reduction. The underlying approach of behavioural economics asserts that consumer behaviour is subject to specific biases and irrational character traits. Behaviour change strategies are said to help consumers to correct deficiencies by activating heuristics that steer them towards changing their actions and habits in directions that would benefit them without impacting individual freedom and autonomy. Interventions based on behavioural insights are therefore described as being able to "advance sustainable consumption 'automatically' through choice architecture and behavioural stimuli" (Reisch, Cohen, Thøgersen, \& Tukker, 2016, p. 238).

However, behaviour change strategies in the context of sustainability governance are far from being uncontested. Behavioral economics has been linked to the reconfiguration of the state-citizen relationship, the rise of particular forms of neoliberalism and new ways of policy making driven by social-psychological discourses (Jones, Pykett, \& Whitehead, 2013). Especially from a food democracy perspective, many inherent political risks and dangers are rarely reflected upon in contemporary discussions. This article, therefore, posits that the rationality of nudging considers sustainability as an allocation of individual responsibilities, raising questions whether collective political strategies are implicitly neglected as approaches to reform the food system and if structural problems can be recognised and addressed at all. Moreover, focusing on individual preferences makes consumers susceptible to corporate interests with possibilities of so-called 'choice architects' (the designers of behaviour change strategies) trying to manipulate consumer preferences for commercial or even personal gain. In the context of steering food consumption and foodrelated behaviours, supermarkets appear as a nodal point of interacting with consumers to steer responsible food choices. Consumers are thereby increasingly governed through marketized activation policies, instead of including them into a wider public debate on political food issues. These developments exhibit traits of a subtle process of depoliticising citizens, which may ultimately create barriers for organizing more forceful political action and to hold 'culprits of unsustainability' politically accountable. Therefore, the possible effects of the rise of behaviour change as a new go-to strategy in sustainable food governance and its impact on the prospects and limits of democratising food systems, need to be further scrutinised. The consideration of the concept of food democracy is important because it facilitates interconnecting discourses of sustainability, logics of governance and potential social and political (side) effects, as well as to interrogate the processes of meaning-making involved in the politics of food.

The article first covers several key arguments and ideas, starting with a short overview of contemporary debates on the benefits and potential dangers of advancing the behaviour change agenda in the context of governing food choices. In the following, the perspective of food democracy underlying the central argument is developed in connection to the notion of responsibilisation within governmentality studies to map the broader democratic implications of upscaling choice editing. Governmentality approaches are viewed as a fruitful supplement to analyse potential anti-democratic tenets within behaviour change strategies because they focus on the micro-mechanisms of how consumers are made responsible for their own conduct. Following this, the article uses data from participant observation conducted at the Expo 2015 in Milan where the "COOP Supermarket of the Future" was introduced: A store built "from the ground up' based on behavioural science to advance sustainable food consumption and anti-food waste behaviours. The analysis shows that rather than to help consumers realise their 'true' preferences, choice architects occasionally design particular environments in order to 'nudge' consumers into resembling a 'fit' for overarching policy goals, thereby potentially decreasing the prospects for democratic legitimation and decisionmaking. Finally, the article concludes with an assessment of potential anti-democratic tendencies that choice architects need to take into account when steering food consumption and food waste behaviours towards sustainable ends. 


\section{Behaviour Change and Sustainable Consumption}

Behaviour change strategies, originally applied in the fields of public health and public finances to steer individuals towards 'better' behaviours such as physical activity and organ donation, is now broadly applied in the field of sustainable consumption to motivate better food consumption, recycling and reducing household food waste production (Mont, Lehner, \& Heiskanen, 2014). In this regard, using behavioural insights to decrease food waste has been applied in Norway, Finland, Italy, Hungary and Portugal among other European nation-states, by agents ranging from private companies, supermarket chains and food bank associations to national ministries (European Commission, 2016).

Within political discourse, behaviour change strategies are now widely known as 'nudges' (as well as choice editing, or choice architecture). A nudge can be considered as "any aspect of the choice architecture that alters people's behaviour in a predictable way without forbidding any options or significantly changing their economic incentives. To count as a mere nudge, the intervention must be cheap to avoid" (Thaler \& Sunstein, 2008, p. 6). The politico-philosophical underpinnings of nudging have been termed by Thaler and Sunstein (2008) "libertarian paternalism," embracing freedom of choice, hence libertarian, leaving individuals in control of their own food choices, and giving them soft nudges to develop their behaviour in a particular (ecologically responsible) direction. While libertarian paternalism provides a justification for behavior change, the actual mechanisms are guided by ideas from behavioural economics and psychology "to explain why people behave in ways that deviate from rationality as defined by classical economics" (Marteau, Ogilvie, Roland, Suhrcke, \& Kelly, 2011, p. 228). Thaler and Sunstein (2008) argue that people suffer from systemic biases that lead to limited awareness, limited information-processing capacity and limited self-control. Nudging is seen as an instrumental technique that helps to overcome the hiatus between irrational and rational behaviours: People should be pushed to develop normative desirable behaviours, which in turn can be employed to either reduce, neutralise or even use ('exploit') systemic biases for policymaking. To this end, choice architecture relies on different instruments to induce desired outcomes, such as providing feedback (helping people to make better decisions), structured information plans or simplifying strategies. We see that behavioural policy options work first and foremost through giving people targeted, yet pre-structured information, containing a sometimes more explicit and at other times more implicit idea about appropriate behaviour change directions, which ideally individuals are to follow.

Subtle forms of influencing human decision-making can potentially have important consequences for enhancing sustainability (for a more comprehensive discussion on the role of nudges in sustainability governance and important tensions, see Bornemann \& Burger, 2019).
As Sunstein explains: "Consumers can be greatly affected by apparently modest and inconsequential aspects of the social environment[,] [s]mall changes in that environment may have a large impact on consumer behaviour, potentially even larger than that of economic incentives" (Sunstein, 2013, p. 2). However, behaviour change strategies do not solely rely on rationalising consumer conduct through incentives. They also steer consumption choices through pro-environmental norms and the promotion of ethical behaviours, i.e., images of how to conduct oneself in light of a specific issue. The target of such interventions is therefore to simultaneously create rational actors (homines oeconomici) and responsible consumers. Hausman and Welch (2010) argue along similar lines that nudging must not be equated with offering information. They reject the idea that informing citizens would be strictly paternalistic, since "providing information and giving advice treats individuals as fully competent decision maker[s]" (p. 127). While there is nothing wrong with informing individuals about the scope of a particular problem and encouraging them to reflect on their own household practices, many nudges aim to "alter people's behaviour by triggering [or blocking] heuristics" (Barton \& Grüne-Yanoff, 2015, p. 343), instead of simply providing information. Heuristics can be understood within this context as "strategies of judgment or decision that are fast and use only a few cues (instead of the totality of the available information)" (Barton \& Grüne-Yanoff, 2015, p. 343). Consequently, heuristics can be used to make people value issues that they would typically overlook by triggering particular emotions or ethical sentiments that provoke 'good' or 'bad' reactions.

Especially in relation to the use of heuristics, nudging has been criticized on various grounds. Hausmann and Welch argue that conveying information subliminally and not by rational means qualifies as diminishing autonomy (Hausman \& Welch, 2010, p. 128), therefore insinuating a state of not fully being in control over one's own actions (Bovens, 2009, p. 4). For example, using emotions and social norms to steer behaviour can lead to the a priori definition of a particular moral template, in which morally correct and wrong conducts are already pre-scripted. This simultaneously raises the question of whether behaviour change strategies are in fact libertarian, or if individual freedom is undermined-or even manipulated. Another line of critical inquiry sees nudges as depriving the subject of the possibility to engage in deliberation or developing the capacity for judgment. John, Smith, and Stoker (2009) assert that given enough time, information and an appropriate environment, citizens may come to optimal judgments for themselves and others, which is considered preferable over an external motivation for the correction of irrational behaviours. Within the literature surrounding the discussion, the worry that choice editing may include implicit anti-democratic tenets is very present. Two important questions remaining are whether these often dormant or invisible possibilities can be further scrutinised, and if so, 
how. Therefore, within the following section, using the concept of food democracy as a normative guidance and the notion of responsibilisation as an interpretive tool to understand the mechanisms behind nudge strategies, we may arrive at a more substantial evaluation.

\section{Food Democracy and the Dangers of Responsibilisation}

The central aim of this section is to link the core concepts of food democracy, sustainability, responsibilisation and behaviour changes to one another. The following argument suggests that although nudges can in principle be designed to enhance democratic capacities of citizens to engage in broader socio-ecological transformations of the food system, more often than not they aim to foster personal pro-environmental lifestyle changes. Thereupon they promote a particular theory of social change and preferred environmental strategies, as well as a specific idea of human nature (Maniates, 2016). While such a focus is not detrimental in a normative sense, it nevertheless establishes a narrow view of how to make food systems more sustainable and runs the risk of undermining pluralist democratic visions of altering current trajectories (Schlosberg, 2004).

As stated in the introduction, the global food system is subject to very different imaginaries of how the structure itself needs to be reformed (or transformed). Across various social movements, we witness the emergence of new practices from food saving, food sharing and urban gardening, which explicitly addresses the negative externalities of material flows and their relation to consumption and wellbeing. They connect diverse social values to the specific materialities of food, deriving a particular political concept from it. For Schlosberg (2004), the appearance of new food practices is of critical importance due to their variety of ethical notions of the good and their application of different principles of justice to a range of situations that require negotiation in a given political context. Meanwhile, behaviour change strategies paint a different picture of future trajectories. Here, the problematisation starts with the inefficiency of the current food system and the irrational decisions of many actors involved, especially individual consumers. Consequently, advised solutions concern the rationalisation of consumer conduct, the adoption of postmaterialist values (being ecologically responsible) and the creation of more transparency with the aid of digital technologies. In this sense, these strategies are less inclined to recognise variety and plurality as normative principles for envisioning social change.

The perspective of food democracy advocated in this article does not automatically prioritise either perspective advocated by social movements or behavioural change strategies. Rather these different imaginaries need to be subjected to democratic deliberation, and thereby to democratic legitimation and control. Food democracy is understood within this article as the:
Popular participation of citizens in formulating foodrelated policies, affecting one of society's most fundamental determinants of wellbeing [which] seeks to respond and contest forces that have managed to disproportionally influence policies to their benefit while curbing the effective participation of other members of society. (Wald, 2015, p. 111)

Such 'forces' can be understood as actors contributing to the spread of economic rationalities within the food system. This threatens the diversity and plurality of autonomous agricultural practices by damaging biodiversity, impacting ecosystem resilience and smallholder subsistence, as well as "the ability of the public to autonomously decide upon possible trajectories toward a future food system" (Fuchs \& Gumbert, 2019, p. 273). The concept of food democracy problematises these developments and is concerned with how citizens can be included as political subjects within food politics. It is helpful for analyzing the normative implications of certain food policy choices and the relationships they constitute, whether between individuals and society or the public and the private sphere, as well as possible normative tensions between autonomy and heteronomy.

In order to apply food democracy fruitfully as an analytical perspective, its conceptual dimensions need to be specified. Taking David Schlosberg's (2004) understanding of justice as the conceptual core of food democracy, there are three interconnected dimensions of justice which he highlights: distribution, recognition and participation (pp. 517-522). Distributive justice helps to uncover inequalities and power differentials in the food system, attributing responsibility to those actors who have the utmost privilege and resources to contribute to meaningful changes. Meanwhile, recognition is central for perceiving actors as being part of the decisionmaking process, rather than external to it. And finally, broad participation of all relevant actors in the food system is necessary to provide them with the ability to speak on their own behalf and ensure self-determination. This is important because the failure to recognise citizens as political subjects may lead to a lack of participation in decision-making, which in turn leads to citizens being excluded from-and therefore not being able to influence-a system of distributive justices. Such a justice-based concept of food democracy validates the call for strengthening deliberative processes in food politics because food futures can only be collectively organised if broad participation is guaranteed with accessible agenda-setting and decision-making. In this regard, we are urged to reflect on the means and not merely the ends of democratic food provisioning, since there is a strong tendency in food governance to focus predominantly on outcomes, such as efficient food supply chains and safe food products. From a democratic standpoint, how these outcomes come about is of equal importance.

The perspective of food democracy developed here is pertinent for evaluating current trajectories towards 
more sustainable food systems. Understanding and practising sustainability in matters concerning food-related politics is far from being self-evident (Carolan, 2012, p. 251). Key questions arise concerning whether environmental sustainability should refer to zero or minimal ecological impact, if economic sustainability for companies means profitability or also to reduce economic inequalities, and whether social sustainability should strive for enhancing social capital or social justice. Given the importance and wide-reaching consequences of addressing these issues, the perspective of food democracy suggests that such questions have to be subjected to democratic institutions and public deliberation and to include societal stakeholders beyond the commodity chain in these debates (DuPuis, Harrison, \& Goodman, 2011). However, critical studies in political science, and more broadly the social sciences, have suggested that a range of strategies are exercised that hinder particular issues from becoming subjected to democratic debate and negotiation. One important strategy in this regard which is specifically discussed within the scholarship of governmentality is 'responsibilisation' (Dean, 2010; Luke, 2016). The concept assumes that responsibility for environmental issues is today increasingly individualised, privatised and attributed to particular actors (such as individual citizens), which complicates efforts to share burdens and to devise collective political strategies.

Governmentality studies develop the idea that by ascribing responsibility, actors are strategically implicated in logics of governance as they are led to practices of self-responsibilisation. A subfield of research within (ecoIgovernmentality studies focuses on the state-citizen relationship and the question of specific tactics that strive to achieve self-governance at the level of the governed individual, as a citizen or a consumer. Individuals should realise that they have to take personal responsibility for making the food system more sustainable. Promoting pro-environmental lifestyle change, such as affecting feelings of personal responsibility, is a central goal of nudge strategies aiming to steer food consumption choices (Hargreaves, 2019). Within behavioural economics, choice architects should aim to manage individual choices "by attempting to correct their [individuals] deviations from rational, self-interested, utilitymaximising cognition and behaviour" (McMahon, 2015, p. 137). It is however important that individuals do so willingly; while their choices may be steered towards contributing to macro-sustainability statistics-i.e., the sum of sustainable behaviours by consumers, such as green purchasing or anti-food waste practices-it is important to preserve, improve and insist upon individual choice (McMahon, 2015, p. 153) in order to uphold individual freedom and autonomous decision-making as central governing principles (Gumbert, 2019). Accepting personal responsibility functions as a gateway to ensure and control the freedom of active subjects by increasingly directing and regulating individuals' beliefs, desires, lifestyles and actions (Foucault, Davidson, \& Burchell,
2008, p. 67). Nicholas Rose (2000) has described these connections as 'ethopolitics,' understood as the government of behaviour, which justifies itself on ethical terms. Instead of merely giving consumers information, "ethopower works through the values, beliefs, and sentiments thought to underpin the techniques of responsible self-government and the management of one's obligations to others" (Rose, 2000, p. 5). Activating responsible attitudes strengthens the effectiveness of nudges because the steering agents (or most external influences for that matter) are removed from sight. Individuals do not directly conform to policy demands but rather to ethical and cultural codes that are understood to be self-evident.

Combining the concepts presented in this section, food democracy and the responsibilisation of individuals to adopt more sustainable behaviours facilitates an evaluation of the dangers inherent in altering individual behaviours to make current food systems more sustainable. Notably: Sustainable goal formation is external to citizens' preferences (denying recognition); citizens should take on personal responsibility for altering personal behaviours (denying collective participation); and citizens take no part in influencing future trajectories of altering food systems (denying the distributive element of justice). In this perspective, it is questionable if behaviour change agendas may contribute to strengthening food democracy, and yet the promotion of individual environmental actions that are straightforward, cost-effective and usually consumeristic is a powerful story of socioecological change. Consequently, this suggests that mass action through comparatively simple and small lifestyle changes is key, by ensuring everyone is on board. This has been described by Michael Maniates (in press) as "magical thinking": If small groups of individuals begin to adopt simple lifestyle changes, others will notice and jump on board. Such a cumulative environmental impact of small behaviour changes will become apparent and gain momentum, ultimately leading to pressure on policy-makers and corporations to change policies and produce cleaner and greener products. While this story can be problematised on numerous grounds (Maniates, in press), a few aspects are especially relevant here for the development of the article's argument. Primarily, if green behaviour change agendas lead to the spread of this rationality among actors in food governance and consumers alike, it seems plausible to suggest that normative principles of food democracy-such as justice and deliberation-will play a less dominant role as a political means for future food governance. Furthermore, there will be less need to adjust structural background conditions that sustain a "politics of unsustainability" (Blühdorn, 2007), and less inclination to support lengthy, complicated and openended democratic processes. In criticism, John (2018) contends how nudging does not necessarily rule out other strategies and that relying on incrementalism (the idea that many small steps may lead to radical transformation) may in fact produce policy responsiveness in 
the face of uncertainty. While these are empirical questions to be answered retrospectively, the design principles of these strategies provide us with insights on whether more democratic solutions are envisioned or not, such as consulting citizens and involving feedback as well as encouraging reflective processes instead of exploiting the non-reflective and automatic systems of individuals. This arguably has consequences for the development of alternative conceptions of a democratised food system. Therefore, the next section gives an account of how visions resting on behavioural-economic ideas currently unfold, how they may contribute to 'greening' the food system and how they may simultaneously undermine more democratic solutions.

\section{Imagining the Future: The Shopping Floor as a Catalyst for Advancing Food Sustainability?}

The following research aims to produce insights on how public behaviour change policies are increasingly imagined as reaching deeper into the everyday food purchasing practices of citizens, and how private actors, such as retailers, are an integral part of these ideas. The case of the "COOP Supermarket of the Future," as part of the Milan Expo 2015, is a promising illustration of these connections since several innovative features are introduced which have the potential to enhance sustainable consumer behaviours. Moreover, it simultaneously signals the willingness of choice architects to instrumentalise the shopping floor as an arena for more effective behavioural interventions. Therefore, it constitutes an example of how food systems are currently imagined as enhancing future sustainability by studying the micromechanisms of steering consumer choice. At first glance, this perspective seems counter-intuitive since behaviour change policies, such as 'nudging,' are being discussed as new public and governmental strategies to steer individual choices and therefore being uninvolved with private sector behavioural interventions (e.g., the activities of supermarkets). In the area of sustainable food provisioning, however, there is an increasing consensus among choice architects that to design effective nudge strategies it is not only important to concentrate on the message given to consumers, but rather when and where to provide it. In this regard, the European Commission considers supermarkets-in the case presented here, EURO COOP-as natural allies because the success of interventions is directly linked to being able to have immediate effects on consumers before they make a purchasing decision in their local supermarket. Public policy, therefore, relies on the cooperation and 'good intentions' of retailers to enact behaviour change agendas on the shopping floor. It is no surprise that national food waste policy schemes, in the UK and Germany for example, have started to clarify the responsibilities of retailers as helping to inform consumers about food waste, to give price incentives to buy food close to expiring and to support simplified date labelling (Federal Ministry of Food and
Agriculture, 2019; Department for Environment, Food and Rural Affairs, 2018).

These logics were prominently reiterated during the side event "Tackling Food Waste: The Consumer CoOperative Way" on October $16^{\text {th }}, 2015$, in Milan. Here, nudging consumers to adjust their food choices was described as modern policymaking by representatives of the European Commission, the European Parliament and the Italian Parliament. The regulation of consumption would target everyone, attributing equal burdens while nevertheless focusing on 'irresponsible' consumers who exhibit 'strange psychological behaviours,' such as wanting to buy bananas in a bunch instead of individually, and whose 'emotions and feelings' needed to be 'rationalised.' Businesses, on the other hand, were already aware of food waste and reduction potentials as they had started to self-regulate their conduct. In terms of efficiency, supermarkets were doing what they could, but consumers were described as 'the last frontier' for regulation. For the European Commission and the General Directorate of Consumer Affairs, tackling food waste has become synonymous with advocating more research on causes and impacts, improving surveillance and monitoring (specifically food waste within supply chains) and encouraging innovation (sharing best practices). Yet concrete policy initiatives focus on the field of food purchasing, predominantly targeting the intersection of supermarkets and consumers. The example of the "Supermarket of the Future" provides first-hand insights on how public and private actors may cooperate in the future to enhance the behaviour change agenda in the field of food consumption. The information presented here was gathered by conducting ethnographic research on three consecutive days in the "Supermarket of the Future" in October 2015 and supported by informal communication with workshop participants and supermarket employees. The descriptive section is based on personal field notes that are subsequently analysed and interpreted by drawing on the theoretical concepts outlined in the above section. Following, the argument will be put forward that while including the private sector in public behaviour change objectives does not necessarily foreclose more democratic solutions (John, 2018, p. 99), it nevertheless strongly suggests a preoccupation with enhancing effectiveness through comparatively small lifestyle choices. As a consequence, particular notions of personal agency and social change are reproduced, i.e., the idea that "we can all be productive agents of change without engaging in difficult political struggle" (Maniates, 2016, p. 142). The potential repercussions of the dissemination of this logic in governing food consumption must be acknowledged.

During the Expo 2015 in Milan, the retail and wholesale company Coop Italy presented the exhibition "Supermarket of the Future," displaying a "place where you see how data and information can change the way we interact with food" (Coop, 2015). Information is presented to consumers on interactive tables, and by sim- 
ply pointing to a product the tables show "improved labels" (Coop, 2015) by telling the story of a product, its properties and its production chain. On a giant information panel, the real-time data related to the point of sale is presented, such as the number of visitors and the products bought. Here, all supermarket purchases are statistically collected and categorised into fruits, beverages, meats and so forth. Behind food counters robots designed "for a new era of automation" and "with dual arms and the ability to feel and see" (Coop, 2015) improve the safe and efficient handling of food products while 3D printers have the potential to reproduce consumers' favourite food in specific forms and colours, with added vitamins. Rather than being a distant possibility, these technologies are viable working realities that may be introduced in supermarkets for consumer interaction if prices for their implementation reduce and their effectivity is proved. In this regard, the market space is specifically catered to help consumers reflect on their food choices, purchase more rationally and 'eco-friendly' by paying attention to food miles, as well as to reflect upon particular cultural values (e.g., to purchase aesthetically 'imperfect' fruits and vegetables). Many of these efforts explicitly or implicitly contribute to raising awareness for the issue of food waste on the shopping floor level.

During the time of the exhibition, the European Commission conducted a field experiment to analyse how consumers would react to these new and innovative techniques for their use within supermarkets (Directorate-General for Justice and Consumers of the European Commission [DG JUST], 2015; Elsen, van Giesen, \& Leenheer, 2015). The study tested if consumers paid attention to price, date labels, nutritional values and environmental information, with a specific interest in consumers' willingness to buy imperfect shaped foods. Although price had a significant effect on consumers' willingness to buy (31 per cent if price reduction would be moderate, 39 per cent if price reduction would be high), when using a persuasive message such as an authenticity (41 per cent) or an anti-food waste message (42 per cent), willingness to buy was slightly higher. However, the combination of both price incentives and an awareness message had an even bigger impact (50 per cent; Elsen et al., 2015). Awareness messages go beyond giving people mere information, because they utilise heuristics to nudge people into conducting certain behaviours, in this case by using cultural values (authenticity) and environmental values (antifood waste) to motivate purchases.

In order to further understand how the 'Supermarket of the Future' operates, supplementary material is required beyond the official documentation, in particular in relation to how it governs consumer conduct and to assess how a more sustainable food system is imagined through specific technologies and behaviour change strategies on the shopping floor (DG JUST, 2015; Elsen et al., 2015; also material handed to visitors on-site). Three components can be seen as instrumental: cate- gorising consumers in terms of food choice; displaying specific information based on consumer type; and using information as a tool for comparing individual behaviours with those of other shoppers. If enabled via a smart mobile device, the supermarket can recognise individual consumers when entering the shopping floor. Based on past purchases, it classifies consumers into one of six categories, which can be locally adjusted to match consumer profiles. In the case of the exhibition in Milan, these profiles included 'Italian Food Lover,' 'Green\&Ethic Consumer,' 'Foodie Consumer,' 'Wellness Consumer,' 'Easy Consumer' and 'Veggie Consumer.' These categories are all positively connoted to help consumers to identify with a consumption label. While shopping, consumer information on the interactive screens throughout the market is displayed according to consumer type to help the customers make choices according to their preferences (e.g., to prevent them from impulse shopping) and to make them feel positive about their consumption choices in the exact moment the food products are picked off the shelf. Moreover, messages and pictures are displayed above the product congratulating consumers on their choice and confirming their decision. For example, if buyers fall into the 'Easy Consumer' category, messages read: "You've chosen an easy to prepare meal, now you're free to enjoy life!" Such an approach has a range of obvious benefits for supermarkets: First, they have a better understanding of who shops in their market allowing them to adjust their product range accordingly as well as to plan ahead more effectively. And second, it is easier to display specific products directly to consumers, for example products of a higher price segment or specific brands. Since this form of advertising is individualised it is more convincing than information targeted at all shoppers. All purchases that are made in the supermarket are further displayed above the shopping area on a largescale information panel, which lists the number of specific categories of products purchased within a day, a week or a month. Here, consumer types are connected to an abstract social context. Messages are displayed to increase transparency concerning what other consumers have purchased and in which quantities, within the same consumer type. Through this tool, it is not only possible to develop a sense of belonging towards a certain consumer group, but also to distinguish oneself from other groups. For instance, it is readily observable for 'Green\&Ethic Consumers' how exactly their eating and consumption habits differ from 'Wellness Consumers' or 'Easy Consumers.' Through the combination of these informational tools, the buyer's choice is designed in multiple ways that are aimed to be beneficial to consumers, retailers and political decisionmakers alike. It is easy to envision that supermarkets designed accordingly can make a valuable contribution to the reduction of food waste on the level of the individual store and private households while fostering 'green' purchasing and ecologically responsible lifestyles coherently and continuously. 
However, from a food democracy standpoint, as outlined in the previous section, these benefits exhibit dangers for collective and autonomous decision-making in the context of food provisioning. First, we have seen that these nudging strategies do not solely aim to give consumers more information and rationalise consumer conduct, but instead rely on values, beliefs and sentiments to motivate techniques of responsible self-government. Citizens are held responsible as conscious consumers to make continuous pro-environmental lifestyle choices to support food sustainability, which is reinforced by mechanisms of social competition to be regarded as 'better' consumers than others. Consumers that subject themselves willingly to logics of food governance are thereby produced through the interplay of technologies, typifications, the ranking of ethical consumption choices and social comparisons. Individualisation is used as a mechanism to promote more effective reductions, which is in stark contrast to participating in efforts to find common solutions. Second, interventions are designed in ways that steer choices through the use of dominant food discourses and values, such as authenticity and antifood waste, making them conform to market requirements. Here, the origin of individual behaviour change aims is externally driven and the citizens' perspective plays no role. Even the chance to recognise particular relations in the food system by giving consumers information about the social relationships behind food production is omitted as the information on the interactive screens are mainly concerned with calculating environmental footprints. By doing so, forms of acceptable and unacceptable food subjectivities are produced that develop responsible attitudes without disrupting the dynamics of consumption and the status quo of the current food system (Rumpala, 2011) because the marketplace is reaffirmed as the central impact arena on the food system. Third, consumers that identify with such ethical and sustainable positions and consumption types can be expected to be mobilised more easily to react to new recommendations. Other subjectivities and lifestyles that may contribute to overall reductions in food waste, and more broadly resource use-such as dumpster divers or food redistributors-are excluded from these locations and are implicitly devalued. In contrast, anti-food waste messages could be designed to inform consumers about the background conditions of food waste generation for instance, rather than simply tying consumption choice to a particular product. This means that citizens have little to no influence and control on which ideas and resources are distributed and which values they would prefer. Ultimately, imagining future trajectories for reforming the food system through these techniques enables corporate preferences to influence debates on sustainability within food politics, and may complicate efforts of conceptualising and actualising sustainability more collectively and democratically.

In sum, placing the responsibility on consumers to adopt more sustainable lifestyles through price incen- tives combined with pro-environmental messages may have positive effects in terms of reduced environmental impact, as suggested by the experiments conducted with shoppers. However, the potential to democratise these nudges by giving information and promoting values beyond greener purchasing decisions has been neglected. While the possibility of more democratic approaches is not foreclosed, nudges sometimes implicitly or explicitly steer in the opposite direction of enhancing dimensions of distributive justice, participation and recognition at the heart of food democracy. The use of flashy digital technologies glosses over the fact that, while it appears that the food system can be more transparently comprehended on multiple screens, the actual relations remain as invisible as before. The concept of food democracy reminds us that in order to arrive at a more just and sustainable food system, the three dimensions of justicedistribution, recognition and participation-must be subjected to the citizens' reflective capacities to counteract the spread of "magical thinking" (Maniates, in press) that green behaviour change agendas will automatically lead us where we want to go.

\section{Conclusions}

Various authors have asserted that normative political concepts, such as food democracy, contain a "vision for the future while at the same time being rooted in the present and being highly political" (Wald, 2015, p. 123). This article has suggested that current economic and political strategies to steer food-related behaviours towards sustainable ends do exactly the same: They constitute building blocks for a future system and promote particular political solutions that are already widely disseminated in the present. When designing sustainable behaviour change strategies in the context of food governance, basic democratic values such as justice and deliberation run the risk of being thoroughly neglected, which in turn creates serious barriers for a democratisation of the food system. Ultimately, there is nothing wrong with encouraging consumers to reflect upon their food choices and to help them to adopt ecologically responsible behaviours. However, if citizens are constantly addressed as consumers and not as political subjects, and they feel they are doing everything they can to transform the system by buying better products, the collective imagination of how the production and distribution of food is organised is severely narrowed. Understanding food politics in this sense replaces democratic deliberation with expert knowledge, dialogue with behavioural modifications, and persuasive arguments with designed options (Gumbert, 2019). Given that these strategies can be expected to further proliferate in sustainabilityrelated fields to target consumption choices, suggestions to inform policy design are all the more important and the concept of food democracy may very well function as a guiding principle to develop a renewed ethics to ground behaviour change strategies. 
Primarily, every consideration should be given to make choice editing as transparent as possible. The call for more transparency, however, does not refer to more and better information about the environmental impact of consumption choices, but behavioural interventions themselves. Citizens must be able to understand who the instigator of an intervention is and what it strives to achieve before making an informed decision on whether they want to comply. This need arises because such strategies are frequently designed to work unconsciously, such as through triggering heuristics that use social and cultural food values or discourses that are rarely consciously reflected upon simply because they are not discussed with others. Instead of relying on these techniques, we should be asking citizens the relevant questions, to engage in dialogue and to give them the possibility of becoming an environmentally conscious citizen, without focusing solely on correcting their irrational, harmful biases. In the short term, the nudge effect may be weaker, but it could contribute to a more comprehensive citizen education in the long run. As a result, nudging could in fact be used to support citizens in "expand[ing] their awareness, experience, and knowledge of the environment in which they live, including their impact on it and its impact on them" (Hall, 2016, p. 604) and promote responsible actions and behaviours beyond the marketplace. For example, nudges may ultimately leave the sphere of consumption behind and focus on social practices (the promotion of collectively engaging with others), the built environment (e.g., better infrastructures for food redistribution) and other material contexts surrounding us. Such strategies have been found to be more apt to promote radical shifts in lifestyles than incremental behavioural changes (Barr, 2015). While this may be viewed as a conventional easy fix it is nevertheless an important step towards democratising nudges.

Second, if questions of when and where to intervene are increasingly important for public policy and the collaboration with private actors as allies is further expanded for greening the food system, this cooperation should be taken seriously. Instead of simply steering consumers towards buying greener products and slightly altering individual lifestyles, the shopping floor could be reimagined as a place for storytelling, for educating people about food worlds and fostering emotions (as part of the system of ethical reasoning; see Nussbaum, 2015) towards appreciating natural resources, soils, and cultivating holistic human-nature relations. It is about recognising diverse agencies which may prompt citizens to participate differently in the future, perhaps away from an individualised approach. That being said, it is equally important that citizens are able to reject such attempts and that the plurality of diverse perspectives is included and justly secured. While this suggestion may seem farfetched-and some will undoubtedly consider it naive, given the power and authority of transnationally operating retailers in the food system-choice architects are absolutely correct to concentrate on the immediate environment where people make decisions. It is for this reason that alternative concepts for the "Supermarket of the Future" need to be brought into dialogue with existing ones. In this regard, a food democracy perspective can simultaneously warn against the dangers of responsibilisation leading to individualisation and depoliticization, while at the same time being constructively applied towards imagining alternate food futures.

\section{Acknowledgments}

I would like to thank the anonymous reviewers and the editors of this thematic issue, Basil Bornemann and Sabine Weiland, for their valuable feedback and comments. The publication of this article has received support from the Open Access Publication Fund of the University of Muenster.

\section{Conflict of Interests}

The author declares no conflict of interests.

\section{References}

Barr, S. (2015). Beyond behaviour change: Social practice theory and the search for sustainable mobility. In E. Huddart Kennedy, M. J. Cohen, \& N. T. Krugman (Eds.), Putting sustainability into practice. Applications and advances in research on sustainable consumption (pp. 91-108). Cheltenham: Edward Elgar.

Barton, A., \& Grüne-Yanoff, T. (2015). From libertarian paternalism to nudging: And beyond. Review of Philosophy and Psychology, 6(3), 341-359.

Blühdorn, I. (2007). Sustaining the unsustainable: Symbolic politics and the politics of simulation. Environmental Politics, 16(2), 251-275.

Bornemann, B., \& Burger, P. (2019). Nudging to sustainability? Critical reflections on nudging from a theoretically informed sustainability perspective. In $\mathrm{H}$. Straßheim \& S. Beck (Eds.), Handbook of behavioural change and public policy (pp. 209-226). Cheltenham: Edward Elgar.

Bovens, L. (2009). The ethics of nudge. In T. GrüneYanoff \& S. O. Hansson (Eds.), Preference change: Approaches from philosophy, economics and psychology (pp. 207-220). Berlin: Springer.

Carolan, M. (2012). The sociology of food and agriculture. London and New York, NY: Routledge.

Clapp, J. (2016). Food (2nd ed.). Cambridge: Polity Press.

Coop. (2015). Shopping today at the supermarket of tomorrow [Pamphlet]. Milan: Coop.

de Young, R., \& Princen, T. (2012). Downshift/upshift: Our choice. In R. de Young \& T. Princen (Eds.), The localization reader: Adapting to the coming downshift (pp. 325-340). Cambridge, MA: MIT Press.

Dean, M. (2010). Governmentality. Power and rule in modern society. London: Sage Publications.

Department for Environment, Food and Rural Affairs. 
(2018). Our waste, our resources: A strategy for England. London: Department for Environment, Food and Rural Affairs.

Directorate-General for Justice and Consumers of the European Commission (2015). Supermarket of the future: Consumer choice and eating habits [Pamphlet]. Brussels: Directorate-General for Justice and Consumers of the European Commission.

DuPuis, E., Harrison, J., \& Goodman, D. (2011). Just food? In A. Alkon \& J. Agyeman (Eds.), Cultivating food justice: Race, class and sustainability (pp. 283-308). Cambridge, MA: MIT Press.

Elsen, M., van Giesen, R., \& Leenheer, J. (2015). Milan BExpo 2015: A behavioural study on food choices and eating habits. Luxembourg: Publications Office of the European Union. Retrieved from https:// ec.europa.eu/info/sites/info/files/bexpo-milan-finalreport_en.pdf

European Commission. (2016). Behavioural insights applied to policy. European Report 2016 (Joint Research Centre Report No. 100146). Brussels: European Commission. Retrieved from http://publications.jrc. ec.europa.eu/repository/bitstream/JRC100146/ kjna27726enn_new.pdf

Federal Ministry of Food and Agriculture. (2019). Nationale Strategie zur Reduzierung der Nahrungsmittelverschwendung [National strategy for food waste reduction]. Berlin: Federal Ministry of Food and Agriculture.

Foucault, M., Davidson, A. I., \& Burchell, G. (2008). The birth of biopolitics. Lectures at the Collège de France, 1978-79. New York, NY: Palgrave MacMillan.

Fuchs, D., \& Gumbert, T. (2019). Power without borders? Transnational corporations in the global food system. In M. Middell (Ed.), The Routledge handbook of transnational studies (pp. 267-274). London and New York, NY: Routledge.

Gumbert, T. (2019). Freedom, autonomy and sustainable behaviors: The politics of designing consumer choice. In C. Isenhour, M. Martiskainen, \& L. Middlemiss (Eds.), Politics, power \& ideology in sustainable consumption (pp. 107-123). London and New York, NY: Routledge.

Gumbert, T., \& Fuchs, D. (2018). The power of corporations in global food sector governance. In A. Nölke \& C. May (Eds.), Handbook of the international political economy of the corporation (pp. 435-447). Cheltenham and Northampton, MA: Edward Elgar.

Hall, C. (2016). Framing and nudging for a greener future. In T. Gabrielson, C. Hall, J. M. Meyer, \& D. Schlosberg (Eds.), The Oxford handbook of environmental political theory (pp. 593-607). Oxford: Oxford University Press.

Hargreaves, T. (2019). Pro-environmental behaviour change and governmentality: Counter-conduct and the making up of environmental individuals. In C. Isenhour, M. Martiskainen, \& L. Middlemiss (Eds.), Politics, power \& ideology in sustainable consump- tion (pp. 87-106). London and New York, NY: Routledge.

Hausman, D. M., \& Welch, B. (2010). Debate: To nudge or not to nudge. Journal of Political Philosophy, 8(1), 123-136.

John, P. (2018). How far to nudge? Assessing behavioural public policy. Cheltenham: Edward Elgar.

John, P., Smith, G., \& Stoker, G. (2009). Nudge nudge, think think. Two strategies for changing civic behaviour. Political Quarterly, 80(3), 361-370.

Jones, R., Pykett, J., \& Whitehead, M. (2013). Changing behaviours. On the rise of the psychological state. Cheltenham: Edward Elgar.

Luke, T. W. (2016). Environmental governmentality. In T. Gabrielson, C. Hall, J. M. Meyer, \& D. Schlosberg (Eds.), The Oxford handbook of environmental political theory (pp. 461-474). Oxford: Oxford University Press.

Maniates, M. (in press). The perils of magical thinking. In A. Kalfagianni, D. Fuchs, \& A. Hayden (Eds.), Routledge handbook of global sustainability governance. New York, NY: Routledge.

Maniates, M. (2016). Make way for hope: A contrarian view. In S. Nicholson \& S. Jinnah (Eds.), New earth politics. Essays from the anthropocene (pp. 135-154). Cambridge, MA: MIT Press.

Marteau, T., Ogilvie, D., Roland, M., Suhrcke, M., \& Kelly, M. P. (2011). Judging nudging: Can nudging improve population health? British Medical Journal, 342. https://doi.org/10.1136/bmj.d228

McMahon, J. (2015). Behavioral economics as neoliberalism: Producing and governing homo economicus. Contemporary Political Theory, 14(2), 137-158.

Mont, O., Lehner, M., \& Heiskanen, E. (2014). Nudging. A tool for sustainable behavior? (Swedish Environmental Protection Agency Report No. 6643). Stockholm: Swedish Environmental Protection Agency. Retrieved from http://www.naturvardsverket.se/Documents/ publikationer6400/978-91-620-6643-7.pdf? pid $=14232$

Nussbaum, M. (2015). Political emotions: Why love matters for justice. Cambridge, MA: Harvard University Press.

Reisch, L. A., Cohen, M. J., Thøgersen, J. B., \& Tukker, A. (2016). Frontiers in sustainable consumption research. GAIA-Ecological Perspectives for Science and Society, 25(4), 234-240.

Rose, N. (2000). Community, citizenship and the third way. In D. Meredyth \& J. Minson (Eds.), Citizenship \& cultural policy (pp. 1-17). London: SAGE.

Rumpala, Y. (2011). "Sustainable consumption" as a new phase in a governmentalization of consumption. Theory and Society, 40(6), 669-699.

Schlosberg, D. (2004). Reconceiving environmental justice: Global movements and political theories. Environmental Politics, 13(3), 517-540.

Schlosberg, D., \& Coles, R. (2016). The new environmentalism of everyday life: Sustainability, material 
flows and movements. Contemporary Political Theory, 15(2), 160-181.

Stock, P. V., Carolan, M., \& Rosin, C. (2015). Food utopias: Hoping the future of agriculture. In P. V. Stock, M. Carolan, \& C. Rosin (Eds.), Food utopias. Reimagining citizenship, ethics and community (pp. 3-13). London and New York, NY: Routledge.

Sunstein, C. R. (2013). Behavioral economics, consumption, and environmental protection (Regulatory Policy Program Working Paper RPP-2013-19). Cambridge, MA: Mossavar-Rahmani Center for Business and Government. Retrieved from http://citeseerx.ist. psu.edu/viewdoc/download?doi=10.1.1.643.4491\& rep=rep1\&type=pdf

Thaler, R. H., \& Sunstein, C. R. (2008). Nudge: Improving decisions about health, wealth and happiness. New York, NY: Penguin.

Wald, N. (2015). Towards utopias of prefigurative politics and food sovereignty: Experiences of politicised peasant food production. In P. V. Stock, M. Carolan, \& C. Rosin (Eds.), Food utopias. Reimagining citizenship, ethics and community (pp. 107-125). London and New York, NY: Routledge.

\section{About the Author}

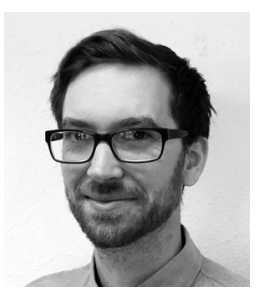

Tobias Gumbert is a Postdoctoral Research Fellow at the Institute of Political Science, University of Muenster. His main research interests include global environmental governance with a particular focus on the governance of food commodities and waste materials, the politics of sustainable consumption and the role of democratic institutions and new forms of governance. 